\title{
El movimiento como detonador de una teatralidad particular ${ }^{1}$ Movement as a trigger for a particular theatricality
}

\author{
Talía Falconi ${ }^{2}$ \\ UNIVERSIDAD DE LAS ARTES, GUAYAQUIL, ECUADOR.
}

Resumen. Este artículo se propone tomar el movimiento como materia prima para el acto creativo en cuanto portador en sí mismo de un tejido de sentidos que es interpretado y reinterpretado, a su vez, por los distintos actores implicados (quien hace y quien observa). Desde esa perspectiva, hay una reflexión puesta en juego acerca de ciertos aspectos que están presentes en mi práctica coreográfica, uno de los cuales deriva en esta investigación: el movimiento como propulsor de una teatralidad particular. Desde allí, son propuestos el estudio y el análisis de los elementos poéticos que intervienen en los procesos de generación de sentido desde el movimiento hacia una cierta noción de teatralidad.

Palabras clave. Teatralidad, Movimiento, Danza, Danza contemporánea, Cuerpo.

\begin{abstract}
The study and analysis of certain elements that intervene in the processes of generating meaning are proposed from the movement towards a particular notion of theatricality (-incarnated in the field of contemporary dance-) fundamentally from a focus centered on the poetic. Movement, as a sensible phenomenon, manifests itself as the bearer of a potential fabric of meaning that is interpreted and reinterpreted in turn by the different actors involved in the artistic event (who does and who observes). From there, a reflection is proposed about certain aspects present in my choreographic practice related to this notion of theatricality that arises from the movement itself, and that also draws on other ideas from the musical, such as those of silence, listening, rhythm and musicality.
\end{abstract}

Keywords. Theatricality, Movement, Dance, Contemporary dance, Body.

\footnotetext{
${ }^{1}$ Los resultados de este trabajo forman parte de la investigación que realicé para la tesis de maestría La hibridez en las prácticas contemporáneas del Ecuador a partir del retrato de una generación, Universidad París 8 , Francia. Tutora: Isabelle Launay.

${ }^{2}$ Bailarina, coreógrafa y docente de la carrera de danza, Escuela de Artes Escénicas, Universidad de las Artes, Guayaquil, Ecuador. Master mención Danza, Universidad Paris 8, Francia. https://www.taliafalconi.com/ https://taliafalconi-federicovaldez.weebly.com/ Mail: taliafal2016@gmail.com.
} 
I am talking to the part of you that never appears

Laurie Anderson ${ }^{3}$

\section{Introducción}

Este escrito se propone reflexionar acerca de la teatralidad que puede originarse en una exploración del movimiento en sí mismo. Pero, ¿a qué movimiento nos referimos?, ¿a qué teatralidad?, ¿cómo y desde dónde abordarla?

El movimiento está en permanente proceso de mutación: ¿en qué contexto, con qué cuerpos se manifiesta?, ¿cuáles factores internos, externos, culturales e individuales intervienen en su producción? Estos son algunos de los aspectos que forman parte de este artículo y que están relacionados con los cruces entre distintos campos artísticos y con la dilución de sus fronteras. Desde esa perspectiva se instaura una disponibilidad específica del cuerpo para la producción del movimiento. No se trata de oponer o negar visiones de técnicas que provienen del campo teatral propiamente dicho, sino de focalizarse en el movimiento desde el cuerpo con el propósito de experimentar otros mundos sensibles que resultarán en otras formas y experiencias escénicas.

Los aspectos aquí abordados surgen de una práctica personal, fundamentalmente en el campo coreográfico y pedagógico, mismos que serán tomados como herramientas para el análisis de esta aproximación hacia una teatralidad particular.

\section{La teatralidad, una postura artística}

Al utilizar el término teatralidad dentro del ámbito de la danza, ¿se le podría estar privándolo del significado propiamente dancístico? Es un hecho recurrente en la historia de las artes tomar prestadas terminologías de otras disciplinas, muchas veces a causa de los intercambios y las contaminaciones artísticas que ocurren durante los procesos de creación. Pero también puede suceder porque dichos términos corresponden a ciertos significados que están asociados a puntos de vista y estéticas en común. Así, por ejemplo, en el campo de la danza contemporánea es frecuente el uso de términos como partitura, dramaturgia o instalación. También se recurre a otros conceptos que ayudan a definir cualidades específicas del movimiento, tales como color, plasticidad o staccato -por mencionar ejemplos comunes-, que provienen de otros campos artísticos y que se han tomado y adaptado al ámbito de las prácticas dancísticas.

La teatralidad es una idea que nace esencialmente del teatro; es un concepto que contiene formas de comprender y habitar el mundo y que se construye gracias a la mirada del otro. No solo se aplica al medio escénico-artístico, sino en los ámbitos sociales, cotidianos y rituales, lo que implica una cierta liminalidad, un estado de tránsito, así como la integración de diversas y simultáneas formas de representación. La intención es dirigir la atención a ese lugar donde aparecen signos, metáforas y sensaciones ocultas, latentes, modos de relacionarse a partir de subjetividades y de percepciones sobre un entorno, y que resulta en la generación de sentido.

Una de las asociaciones más comunes con este concepto está estrechamente relacionada con el uso de técnicas y estrategias metodológicas que provienen directamente del teatro, es decir, que se basan en la construcción de una situación y/o de personajes explícitos. Aclaro que la intención aquí no es abordar una danza teatral a partir de técnicas y recursos actorales únicamente, ni tampoco en el sentido de lo espectacular, que en algunos

\footnotetext{
${ }^{3}$ Frase tomada de Lecture 2 de Laurie Anderson, emisión transmitida el 23 de marzo de 2021 por Zoom.
} 
casos puede referirse a los artificios exteriores ${ }^{4}$, a la espectacularidad, la exageración o la sobreactuación del gesto danzado. A pesar de que Patrice Pavis admite que "el concepto tiene algo de mítico, de demasiado general, incluso de idealista y de etnocentrista" (434), con teatralidad nos referimos a aquello relacionado con momentos escénicos que sugieren signos, metáforas y/o sensaciones ocultas, latentes, que implican una visión particular desde las subjetividades y las percepciones sobre nuestro entorno.

Pero en el campo de la danza, ¿acaso no podríamos decir "danzalidades"? Según el catedrático chileno Alfonso de Toro, la teatralidad "no posee una estructura tradicional, sino una estructura híbrida" por la enorme e infinita posibilidad de procesos dinámicos de representación (18).

Por otro lado, podemos decir que, sin duda, desde el corazón mismo de la danza es posible desarrollar una poética sustentada en un vocabulario propio y autónomo. Sin embargo, el uso de la noción de teatralidad constituye una postura asumida que implica desde la danza- una idea de hibridez y de cruce con el teatro. También es una postura de carácter político porque implica contaminación, mezcla y transgresión de fronteras. Pero, sobre todo, esta visión de la teatralidad se concentra y se manifiesta en el hecho escénico producido desde el "itinerario interior del movimiento" como una fuente de una acción constante que genera sentido:

En realidad, el arte no puede soportar ningún límite: esto es lo que quiere significar Mikel Dufrenne cuando reivindica "una estética sin trabas" que no tiene otra ley que la de la movilidad de una obra artística, sin fronteras, apátrida y salvaje (Bernard 31) ${ }^{6}$.

¿Cómo se construye el movimiento de los personajes, las situaciones y hasta de las ideas que queremos tratar? ¿Cómo se puede interpretar el movimiento desde una posición alejada de ideas preconcebidas o significados forzados? Estas inquietudes conllevan contradicciones importantes a las que en algún momento nos hemos visto confrontados como creadores en nuestros espacios de trabajo.

\section{El movimiento como materia prima}

En los inicios de mi trabajo creativo con la agrupación Río Teatro Caribe en Venezuela ${ }^{7}$, a principios de los años noventa, los procesos de creación tomaban como punto de partida temáticas de orden narrativo muy específicas. Generalmente, la danza se desarrollaba y destacaba en los momentos culminantes de una situación teatral previamente comprendida y aceptada como tal. Es decir, primero la situación teatral era planteada y luego, una vez

\footnotetext{
${ }^{4}$ Si bien en el Diccionario del teatro, Patrice Pavis admite como frecuente el uso de "teatralidad" para aludir a lo espectacular de la escena y determina un valor o una valorización de la teatralidad, a fin de cuentas califica este término como "banal y poco pertinente" (434-435).

${ }^{5}$ Esta es una descripción que utilizaba Alwin Nikolais con el objetivo de hacer una distinción entre motion y mouvement en el programa "Day and night: Alwin Nikolais". Youtube, cargado por CUNY TV, 5 feb 2011, https://www.youtube.com/watch?v=atmek4ra-UU.

${ }^{6}$ La frase citada del filósofo francés Mikel Dufrenne es tomada de Vers une esthétique sans entraves (10-18).

${ }^{7}$ Soy fundadora y fui codirectora de la compañía Río Teatro Caribe hasta 2010.
} 
establecida, se generaba el movimiento. La danza muchas veces se instalaba como la prolongación de esa situación teatral, en el sentido de estar contenida en una estructura narrativa con un argumento comprensible. De esta manera, la aparición de momentos danzados de naturaleza más abstracta se justificaba dentro de esa línea argumental priorizando un pensamiento de "lo teatral" como una organización narrativa establecida.

Después de varios años de explorar en esa dirección, comencé a trabajar de modo inverso: investigando cómo las distintas formas de tratar y abordar el movimiento en sí mismo llegan a instaurar una cierta teatralidad. Desde 2010 esta visión se hizo más evidente a partir de la colaboración con el músico y compositor argentino Federico Valdez en México, con quien generamos aproximaciones en las que se fortaleció la relación danza/música. En ese momento retomé con más fuerza las problemáticas que surgen del propio movimiento y de sus sentidos implícitos. ¿Cómo y por dónde empezar una creación? Esta podría parecer una pregunta a la vez básica y banal, sin embargo, desde el punto de vista de la exploración del movimiento toma otro sentido (y otra profundidad). Por momentos, esos instantes de teatralidad que aparecen, podrían evocar lo que Arthur Adamov llamó "el contenido oculto, latente" (ctd. en Pavis 434-435).

Evidentemente, existe una variedad de caminos a seguir que va a depender del sentido que se quiera (o no) asociar al movimiento. Y por cierto, será el espectador quien recree finalmente su propia experiencia de teatralidad, pues aunque el coreógrafo y los intérpretes pretenden abonar cierto enigma, cierta ambivalencia o una lectura abierta a su propuesta, finalmente es la mirada del público la que dará un sentido a lo que ve. Es por ello que no se pueden obviar algunas líneas de sentido a las que remiten ciertos movimientos en contextos determinados. Por ejemplo: el abrazo entre un hombre y una mujer. Aunque nos enfocáramos solo en su movimiento, en sus calidades, direcciones y duraciones, alejándolas de todo tipo de vínculo emocional, no dejaríamos de ver en este gesto un tipo de relación (de pareja), incluso acompañado con un cierto contenido emocional en juego. Difícilmente ese gesto podría desprenderse de un imaginario que es producto de una construcción social.

Pero, ¿qué pasa si son gestos y movimientos de naturaleza más abstracta? Por ejemplo, digamos, un hombro que guía al resto del cuerpo, como un motor de movimiento. Aparentemente no estaría asociado a un significado "reconocible y asimilado en la sociedad" (Barnsley, ctd. en Falconi, La hibridez 84) ${ }^{8}$. Sin embargo, gracias al tratamiento cualitativo de este movimiento y a una relación espacio/tiempo específico, podría producir un efecto de una gran expresividad. Este movimiento por sí solo podría ser el germen de otra forma narrativa y encaminarse hacia una teatralidad específica que produciría otras líneas de sentido.

En el momento en que una experiencia escénica se confronta con la mirada del espectador, se instala una "relación forzosamente teatral" (Louppe 414), pues este va a interpretar lo que está viendo según su propia sensibilidad. Pero, ¿se podrían reconocer ciertas señales y huellas a partir de las cuales definir una teatralidad desde el movimiento?

Hay muchas maneras de abordar y distinguir el trabajo con el movimiento, que es definido por las características estéticas de cada creador. El sentido que se despliega desde el movimiento no está asociado necesariamente al entendimiento racional de una línea argumental; muchas veces es un llamado a despertar otras maneras sensibles de entender y habitar el mundo desde/hacia el movimiento.

Con el propósito de generar herramientas que puedan ser útiles para el análisis, propongo organizar el movimiento, en principio, a partir de tres distinciones, para englobar su

\footnotetext{
${ }^{8}$ Expresión tomada de la entrevista realizada a Julie Barnsley por Falconi en su tesis de maestría (La hibridez 84).
} 
tratamiento dentro de la práctica escénica contemporánea. Estas son categorías en las que confluyen algunas miradas que vienen de los campos del teatro y la danza:

1. El movimiento comprendido como acción concreta. Es decir, relacionado con un verbo, con una acción que compromete al cuerpo a realizar tareas específicas. (Por ejemplo: caminar, saltar, girar, etc.). Desde allí se abre la posibilidad de realizar una composición a partir de una partitura o instrucción de acciones.

2. El movimiento como código. Este puede tener la forma de un gesto con un significado reconocible del orden de lo simbólico (el abrazo antes ejemplificado). Esta categoría incluye las figuras y los códigos de movimiento de un estilo determinado, de una técnica o deporte identificable. Se podrían incluir también los métodos de formación en danza que desarrollan una corporalidad característica (el ejemplo más básico sería la técnica del ballet clásico, pero un ojo más especializado puede reconocer, por ejemplo, la técnica Graham).

3. El movimiento como naturaleza abstracta. En esta categoría no se incluye ninguna de las acepciones anteriores. El foco está en sus propiedades físicas, en su relación con la gravedad, el espacio y el tiempo. Esto no quiere decir que en los tratamientos antes descritos estas propiedades físicas no se tomen en consideración, pero el objetivo formal y expresivo sería otro. En el campo creativo, incluso los coreógrafos que trabajan con una base narrativa más explícita - por ejemplo, los que construyen personajes danzados- se refieren a esa instancia de trabajo como una elaboración técnica del movimiento.

Estas distinciones se pueden combinar aleatoriamente y desde un acercamiento más detallado devenir más complejas a interpretar según el contexto específico en que se producen. ¿Cuándo/dónde/quién produce el movimiento? ¿Cuándo/dónde/quién observa el movimiento? Por ejemplo, el gesto de mirar hacia arriba podría tener un sentido simbólico, crear un vínculo con un mundo superior. Pero ese mismo gesto en otro contexto dancístico puede estar alejado de toda referencia y asociación simbólica y ser simplemente la acción concreta de mirar hacia arriba.

Pongo a consideración estos posibles tipos de tratamiento del movimiento porque podrían posibilitar la visualización de una distinción más clara entre cuerpo y movimiento. Propongo una idea de separación y distancia como base de una aproximación hacia esa teatralidad, en el sentido de poner la atención en la acción que produce el movimiento. Evoco la frase esclarecedora del investigador en danza francés Hubert Godard: "es el gesto el que fabrica el cuerpo a cada instante" (ctd. en Louppe 69). Si bien en él está implícito el cuerpo, pues todo es cuerpo, sea este visible o no, colocar la atención y la intención en el movimiento es una manera de salir del cuerpo. Tal acercamiento podría ser liberador a nivel creativo porque implica salir de uno mismo.

No se trata de crear un antagonismo entre mi cuerpo y el movimiento que se produce, ellos están íntimamente ligados, pero la idea de separación y distanciamiento pone enseguida en juego una conciencia espacial, lo que facilita una manera de organizar y desorganizar el espacio y el tiempo escénico. Por supuesto, dentro del campo exploratorio es una idea que está en el orden de lo ficcional y que bien podría contemplar una cierta disociación al focalizarse en ese espacio intermedio entre movimiento y cuerpo. Se trata solo de una mirada que podría instalar conexiones, escuchas y relaciones singulares con cada uno de los elementos (objetos, personas, materiales y recursos) que intervienen en los distintos procesos de creación. 


\section{Cuerpo y subjetividad}

Los procesos creativos nacen de maneras impredecibles: ideas sueltas, sensaciones, imágenes evocadoras, relaciones con objetos y materiales, emociones, sonidos, impulsos inexplicables. En el campo de la danza, el acto creativo busca su inspiración a través del movimiento y muchas de las técnicas parten de la construcción de un estado físico, de una corporalidad específica, de cierta presencia que determina una manera de estar en un aquí y ahora, de habitar un presente. ¿Cómo percibimos nuestro entorno, cómo nos percibimos a nosotros mismos? Si cierro los ojos, imagino ver mi propio cuerpo dentro de una proyección subjetiva9. Me introduzco en una recreación escénica que compone un universo, una existencia efímera, que magnifica el instante como una experiencia temporal única e irrepetible. En esa disyuntiva que separa lo que es uno y lo que es el otro, se proyectan instantes cargados de una teatralidad donde resuena la circulación entre un mundo interno y otro externo. Una dualidad, una oposición, un estado de tensión (propio de las dinámicas del movimiento). La subjetividad se sitúa en estrecha relación con el imaginario y las experiencias singulares, con las sensaciones y los sentidos que nos interpelan y conmueven, y que por ahora solo reafirman que seguimos habitando en este mundo.

La bailarina y coreógrafa inglesa/venezolana Julie Barnsley sugiere maneras de conectarse y de percibir el mundo "desde un cuerpo profundamente introspectivo, íntimo y subjetivo" (12). La subjetividad es entendida como una percepción del entorno que se puede traducir en la generación de sentido a través - fundamentalmente- del cuerpo (en el espacio y el tiempo), en un movimiento que se proyecta hacia el otro (en este caso el espectador) y se reinterpreta desde su mirada. El movimiento y el gesto hacia el otro son medios de comunicación de subjetividades, contrariamente a la idea de que la subjetividad es un retorno a uno mismo. En palabras de Simone de Beauvoir: "mi subjetividad no es inercia, retraimiento en uno mismo, separación, sino al contrario, movimiento hacia el otro" (17). Entonces, ¿cómo afecta la subjetividad a un imaginario y compone una corporalidad?

La necesidad de comunicar desde el movimiento en sí mismo a través de un cuerpo pensante vinculador de mente y espíritu abre las puertas para que aparezcan otras experiencias humanas -que son esenciales en el campo de la escena- desde lo sensible. Tal es el ejercicio de la actividad sensorial y de los sistemas perceptivos involucrados, uno que se aleja de la lógica racional y que es más cercano a un pensamiento del cuerpo: un pensamiento que produce movimiento con objetivos distintos a los de una lógica de tipo racional.

Hablamos entonces de los cuerpos y sus infinitas posibilidades de interpretar y percibir la vida, de sus espacios íntimos y sus espacios compartidos. De un solo cuerpo que es capaz de transformarse en mil cuerpos. De la inteligencia y las energías visibles y no visibles de la materia. De lo no expresable verbalmente. Del movimiento, la impermanencia y la transformación como las únicas constantes (Barnsley 13).

\footnotetext{
${ }^{9}$ Cito al filósofo venezolano Enzo del Búfalo: "Y lo sustentan como subjetividad: en la singularidad, la subjetividad se constituye como mundo y el mundo es una proyección subjetiva de la subjetividad corporal. El mundo primordial es pura subjetividad proyectada" (189).
} 
Ahora bien, ese cuerpo, o esa transformación en mil cuerpos, está repleto de huellas de los contextos de donde provienen, que son determinados y que a su vez pueden constituir una postura política. Un cuerpo en escena, ¿a qué espacios traslada (o no) a los cuerpos de los espectadores? ¿En qué espacios de la imaginación y de los afectos está presente?

Paradójicamente, es maravilloso cuando el cuerpo finalmente se pierde, se olvida de sí mismo. Puede existir entonces un sentimiento de gran liberación, una transformación poética del cuerpo. Dice el bailarín de danza butoh Kazuo Ohno: "cuando nuestra danza enloquece" (Ohno y Ohno 202) ${ }^{10}$ el sujeto se olvida de sí mismo, deja fluir la conexión entre la imaginación y los sentidos. $\mathrm{O}$ en palabras de la bailarina y coreógrafa francesa Françoise Dupuy: "Una danza tiene lugar cuando no hay una forma, sino una transformación posible, una experiencia de movimiento" (ctd. en Louppe 283). El cuerpo cotidiano desaparece para exponer un imaginario que corresponde a un mundo interior ${ }^{11}$. Esa transformación del cuerpo puede producir teatralidades relacionadas con una subjetividad particular y sentidos palpables sin la necesidad de explicar racionalmente por qué se realizan (o no) los movimientos.

Las reflexiones que surgen desde la experimentación y la búsqueda $-\mathrm{o}$ sea, desde la práctica- parecieran no tener fin. Se trata más bien, cada vez, de un ciclo de inicios, de preparaciones hacia algo nuevo. Quisiera esbozar dos aspectos que propongo para establecer ciertos vínculos con esa teatralidad particular desde el movimiento: la escucha y el ritmo. Considero pertinente visitarlos porque que están siempre presentes durante los procesos creativos dentro de este campo amplio que comunica con lo sensible. A partir de ellos seguiré desarrollando esta idea de separación y de distanciamiento. Para ello me permito insertar algunas descripciones intercaladas de pequeños fragmentos de dos obras propias muy distintas entre sí. La primera: Música para pelucas, estrenada en 2011 en la Ciudad de México, fue la obra fundacional de la colaboración que vengo realizando con el músico y compositor argentino Federico Valdez. La segunda: sigue Corriendo, la realicé con estudiantes de la Universidad de las Artes de Guayaquil, Ecuador, en 2019.

\section{La escucha como una idea de teatralidad}

Pauline Oliveros, compositora de música experimental y pionera de la música electrónica de los años cincuenta en Estados Unidos, creó una práctica llamada deep listening ${ }^{12}$. Se trata de una experiencia sensorial que consiste básicamente en la escucha profunda y atenta, como un acto consciente, para diferenciar la audición de la escucha y que consistiría en la concentración real y completa en el objeto de escucha con el fin de captar toda la complejidad e intensidad del sonido. Me parece importante mencionar mínimamente ciertos puntos de vista que vienen de la música, en la que se han desarrollado modos de escucha definidos. Subrayo la atención al objeto de escucha, que en nuestro ámbito se podría trasladar, además de la escucha del sonido, a la atención consciente que damos al movimiento.

\footnotetext{
${ }^{10}$ Cita completa de Kazuo Ohno: "Nuestras mentes están llenas de ideas preconcebidas sobre lo que es una sombra o sobre la forma que debe tener una flor. Pero cuando nuestra danza enloquece, nosotros ya no estamos ligados a estos contenidos. Al volvernos locos, en un primer momento no sabrás dibujar esa flor. Pero justo cuando te hayas olvidado de ti mismo, la flor aparece. Tú no puedes explicar por qué, pero está justo allí” (Ohno y Ohno 202).

${ }^{11}$ Pongo para su reflexión lo que Eugenio Barba y Nicola Savarese refieren como cuerpo ficticio: "no en la ficción dramática sino en cuerpos que concentran todas sus fuerzas en una cierta zona ficticia, que finge no una determinada ficción sino una especie de transformación del cuerpo cotidiano a un nivel pre-expresivo" (23).

${ }^{12}$ Se trata de Deep listening. Una práctica para la composición sonora de Pauline Oliveros.
} 
No estoy sentada, ni parada. Escucho el sonido enérgico de la guitarra que llega del fondo del escenario.

Se encienden las luces suavemente. Estoy detenida en medio de la acción de sentarme en una silla, sosteniendo mi cadera en el aire, mis manos apoyadas en el asiento de la silla sostienen mi peso. Tiempo detenido, suspendido, a la escucha..., mi pie dibuja unos círculos en el aire, lo que produce el impulso de incorporarme para desplazarme a otro punto, a un espacio minúsculo, delimitado por un pequeño tapete rojo ubicada en el proscenio del escenario. Nuevamente quedo detenida y atenta en la mitad de otra acción, en tensión. Otro gesto que queda interrumpido. A la escucha... ${ }^{13}$

Esta descripción corresponde al inicio de la obra Música para pelucas. Esta pieza coreográfica confronta relaciones y variaciones de la escucha entre sonido/movimiento/silencio/quietud. La obra es un dueto (guitarrista-bailarina), donde de manera recurrente suceden largos momentos de quietud, de gestos interrumpidos en la mitad de las acciones. El sonido de la guitarra contrasta con la bailarina inmóvil en medio de la acción de sentarse. A lo largo de la pieza, la acción de ella consiste en sacarse varias capas de pelucas superpuestas, mientras repite de manera idéntica entradas y salidas desde/hacia un pequeño tapete rojo. Hay un diálogo, una escucha activa que se instala entre el guitarrista y la bailarina. La atención está dirigida al sonido de la guitarra que los une. Se instalan largos y provocativos momentos de quietud y de silencios; son como estados de alerta en medio de las acciones concretas que se producen.

La escucha sería un acto donde los sistemas perceptivos involucrados están activos, alertas y conscientes. En el caso de la obra Música para pelucas, la escucha y el silencio son uno de los ejes principales de ese trabajo. No solo se perciben en los momentos de quietud o detención del gesto, donde la concentración y la atención al entorno son más propicios, sino que también se puede observar el traslado de un espacio interno hacia uno externo. Por ejemplo, el gesto del movimiento circular del tobillo es el que produce el desplazamiento hacia el pequeño tapete rojo. El movimiento queda en suspenso entre el sonido, los silencios y el movimiento, entre los contactos y los apoyos con los elementos en escena (las tres sillas, el pequeño tapete rojo y el piso), entre lo interno y lo externo, entre el sentir, el movimiento y la percepción del espectador. ¿Se podría considerar, acaso, un puente entre la "propiocepción" a la percepción de un entorno?

Enzo del Búfalo diferencia la percepción de la propiocepción de la siguiente manera:

La percepción se distingue de la propiocepción porque no solo existe diferencia entre el sintiente y lo sentido, sino separación. Por ejemplo, si cierro los ojos y concentro mi atención en mi brazo tengo una propiocepción, y al abrirlos puedo percibirlo como apoyado en la mesa. Podríamos decir que en el primer caso siento

\footnotetext{
${ }^{13}$ Obra coreográfica Música para pelucas, de Talía Falconi y Federico Valdez.
} 
mi brazo como mi propia subjetividad y en el segundo como algo objetivo (Del Búfalo 40).

Esta distinción y separación que propone entre el sintiente y lo sentido forma parte de lo que está comprometido en la escucha, y muchas veces también sucede de manera simultánea en la práctica: "Cada gesto se sustenta en una percepción; un enredo entre el sentir y el mover funda nuestra relación con el mundo" (Roquet 82).

Los momentos de quietud y los silencios son elementos que magnifican la escucha, además de demandar un alto grado de concentración y de disponibilidad física para interactuar con el entorno. En esos lapsos de atención silenciosa se manifiestan momentos de gran expresividad que instalan un tiempo de teatralidad. La escucha desde/hacia produce en el movimiento instancias llenas de teatralidad, sin necesidad de recargar en él otros significados o interpretaciones adicionales.

La escucha se entiende, entonces, como un acto propioceptivo y de percepción de un entorno a la vez. Esta acción demanda un estado de disponibilidad física que compromete la manera en que el cuerpo distribuye su peso y en que la fuerza de la gravedad afecta las distintas modulaciones de la tensión muscular. Retomo, para una mejor explicación, "el sentido del peso subjetivo" de Hubert Godard, relacionado con la oreja interna y la posición de la cabeza en el espacio (ctd. en Roquet 64-65), es decir, el vínculo directo de la escucha con el manejo del equilibrio y el sentido de la orientación. Además, agrego la mirada como un puente que comunica con un mundo exterior, que percibe el espacio alrededor y lo proyecta hacia afuera.

Por otro lado, la escucha abre también una dimensión temporal que no solo se limita a un espacio, sino a la interacción y el juego con el silencio. De manera intuitiva comprende un afuera/adentro, un interior/exterior. La interacción y el juego se presentan en el sentido de la comunicación y de la necesidad de accionar en un cierto momento específico (lo cual remite a la idea de timing). Es decir, puede ser una forma de organización intuitiva de la acción escénica que podría también estar en el orden de lo ficcional.

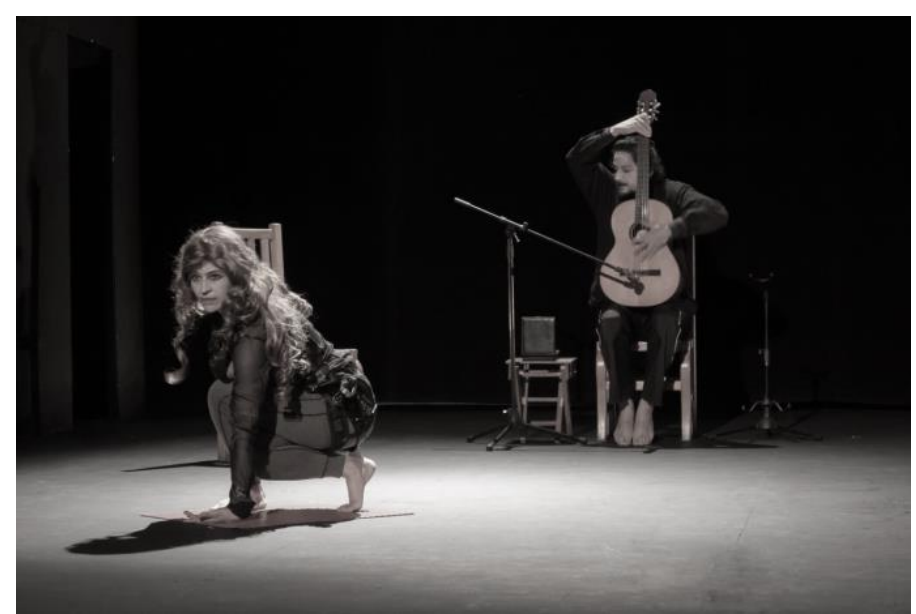

Fig. 1: Talía Falconi y Federico Valdez.

Obra: Música para pelucas. Estreno 2011. México. 


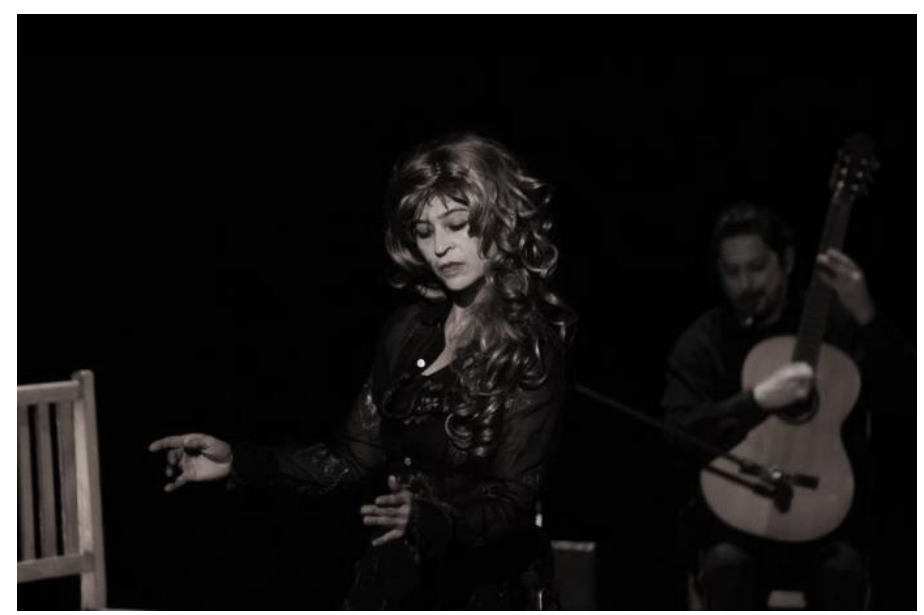

Fig.2: Talía Falconi y Federico Valdez

Obra: Música para pelucas. Estreno 2011. México.

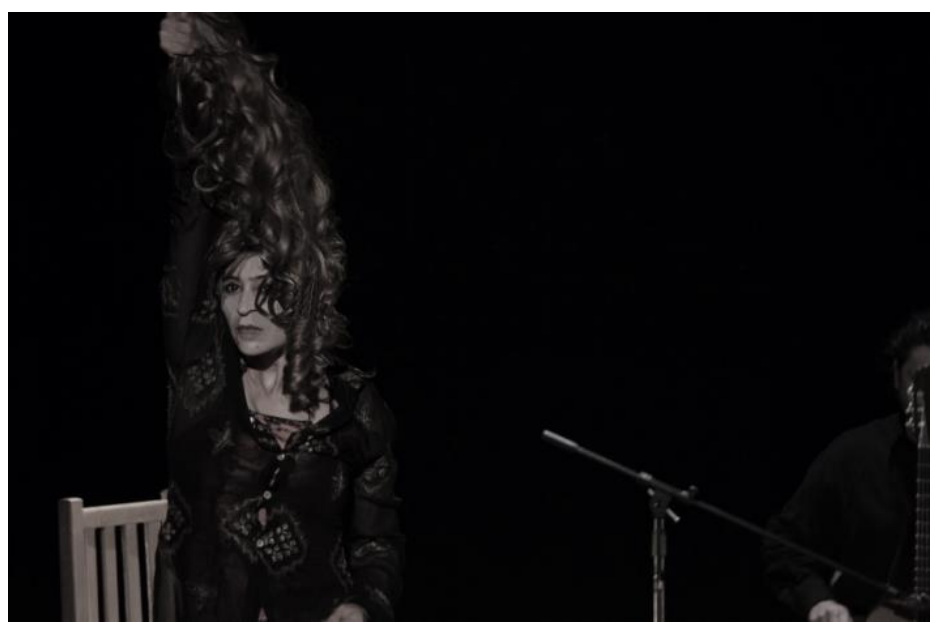

Fig. 3: Talía Falconi y Federico Valdez

Obra: Música para pelucas. Estreno 2011. México.

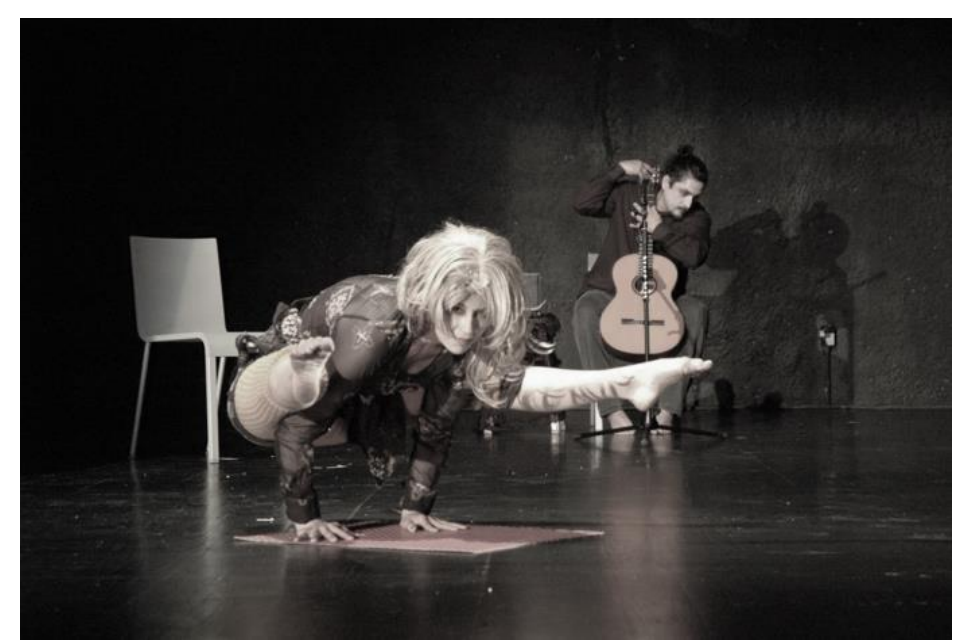

Fig. 4: Talía Falconi y Federico Valdez

Obra: Música para pelucas. Estreno 2011. México. 


\section{El ritmo como una idea de musicalidad escénica}

Mientras se desplazan emiten un sonido que acentúa sus pisadas y su vínculo a la tierra, pareciera que lo hicieran desde hace décadas o siglos, se percibe un cierto agotamiento.

Parecen mantener un ritmo regular, con una cierta monotonía. Siempre continúan hacia adelante, con el peso de la cabeza que se deja caer y que deambula ligeramente a los costados.

De vez en cuando se detienen, o alguno de ellos se queda en el camino, pero cada vez el resto del grupo los recoge y continúan con el mismo desplazamiento sin fin ${ }^{14}$.

En 2019 realicé un montaje coreográfico con estudiantes de la Universidad de las Artes en Guayaquil, Ecuador. Luego, en 2021, se estrenó una adaptación cinematográfica basada en esa obra, sigue Corriendo ${ }^{15}$. La obra parte del movimiento de un grupo/colectivo de jóvenes que corren sin parar. El grupo atraviesa diversas geografías, generalmente con un paso que pretende ser estable, pero en realidad está siempre fluctuando entre aceleraciones y desaceleraciones. Durante este desplazamiento infinito suceden momentos efímeros de relaciones entre ellos, ya sean afectivas, físicas y/o gestuales. La versión escénica no utiliza música de fuentes externas, únicamente los sonidos de las respiraciones y de algunas expresiones verbales que los bailarines emiten y que sobresalen en ciertos momentos: acompañando, acentuando, liderando y contraponiendo los gestos y los movimientos del grupo.

La exploración y la reflexión acerca del tiempo del movimiento ha sido una preocupación constante desde hace varios años en mi práctica como creadora y docente. Muchas veces he comenzado una etapa de exploración a partir de la rítmica respiratoria y como consecuencia del gesto que se produce. Podría atreverme a decir que la respiración compone el gesto, así como el gesto compone un cuerpo. Es la idea de ritmo (en relación con la idea del timing) como una manera intuitiva de organización. Digo intuitiva, que puede serlo en una primera fase, porque no hay una razón evidente, está en el orden de la experiencia sensorial no comunicable de manera discursiva. Desde esa instancia la respiración juega un rol muy importante porque dialoga con las distintas conexiones afectivas y expresivas.

¿Cómo puede el ritmo manifestar una visión de teatralidad?

El ritmo instala un juego de tensiones dinámicas (cambios de velocidad, acentos, pulsos, clímax, pausas, repeticiones, etc.), es decir, instala una idea musical del movimiento con un potencial expresivo infinito. Además de su dimensión temporal, relacionada con la manera de organizar las acciones y eventos, el ritmo también establece una relación estrecha con una dimensión espacial y, en consecuencia, juega con la composición coreográfica.

Retomo las palabras de Chapuis, Gourfink y Perrin en su publicación Componer en danza: "En efecto, el ritmo tiene consecuencias sobre muchos otros aspectos de la obra: sobre la musicalidad, sobre la forma expresiva, sobre la construcción de sentido o sobre la modulación de la relación que se establece con el público" (375).

La acción concreta y recurrente de correr en la obra sigue Corriendo, así como todas las relaciones que suceden entre los bailarines, es tratada desde esa relación respiratoria/rítmica/gestual. A partir de ese vínculo se plantea la organización de

\footnotetext{
${ }^{14}$ Descripción de la obra coreográfica sigue Corriendo de Talía Falconi.

15 sigue Corriendo es una obra coreográfica, resultado de mi proyecto de creación-investigación realizado con estudiantes de danza en la Universidad de las Artes de Ecuador. Culminó en junio de 2021 con la realización de una película con el mismo nombre. La fotografía de la película fue realizada por Diego Falconi y la música por Federico Valdez.
} 
movimientos, cuerpos, elementos y recursos escénicos en el espacio. En otras palabras, los gestos y los cuerpos que se desplazan componen un espacio a partir de una experiencia rítmica y esto influye directamente en cómo se produce y se recibe el hecho escénico.

Estos jóvenes bailarines están concentrados en mantener un pulso grupal, colectivo, donde la relación respiratoria/rítmica/gestual no solo obliga a mantener un fuerte trabajo de escucha, sino que conforma el movimiento del coro, lo que la convierte en el germen de una teatralidad latente. En este caso, la teatralidad se manifiesta a partir de la comunicación rítmico-musical entre ellos y con el espectador.

A manera de cierre, quisiera resaltar otro aspecto de este trabajo coreográfico que vincula una aproximación a la teatralidad con una conexión muy particular con el mundo andino. De manera completamente espontánea resaltan algunos movimientos: el ritmo de los desplazamientos (sonoro y visual), la manera como el grupo atraviesa el espacio y avanza, la corrida de pasos pequeños, el tiempo fuerte que cae en el piso, el peso de la cabeza suelta, la modulación del tono muscular que oscila entre pequeñas caídas y recuperaciones. Todas estas características gestuales pueden estar asociadas con ciertas reminiscencias de algunas danzas que están presentes en las fiestas populares de comunidades indígenas de la región andina del Ecuador.

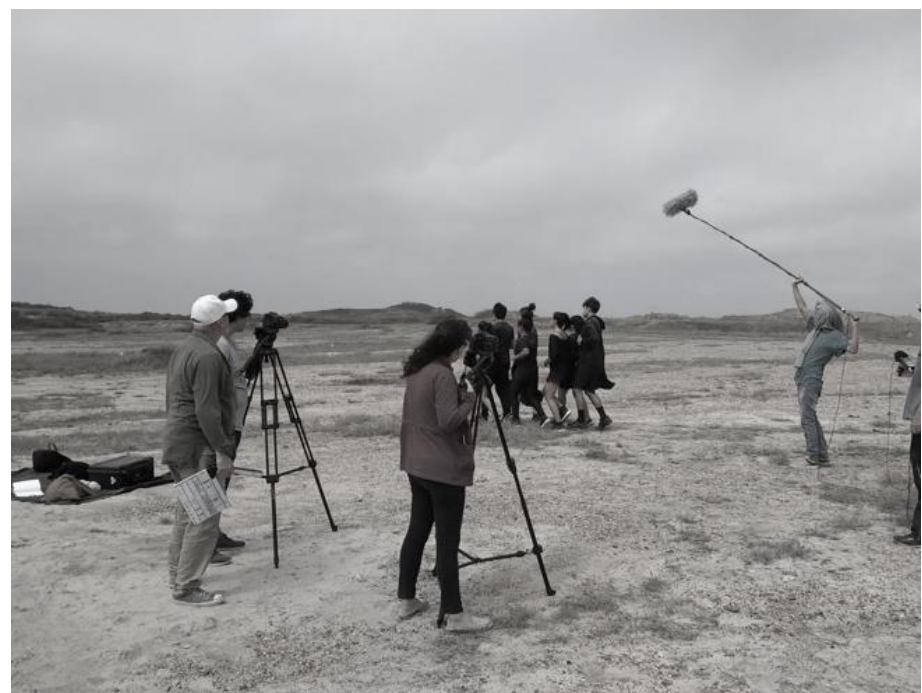

Fig.5: Realización de la adaptación cinematográfica de la obra coreográfica sigue Corriendo de Talía Falconi. Estreno 2021. Ecuador. 


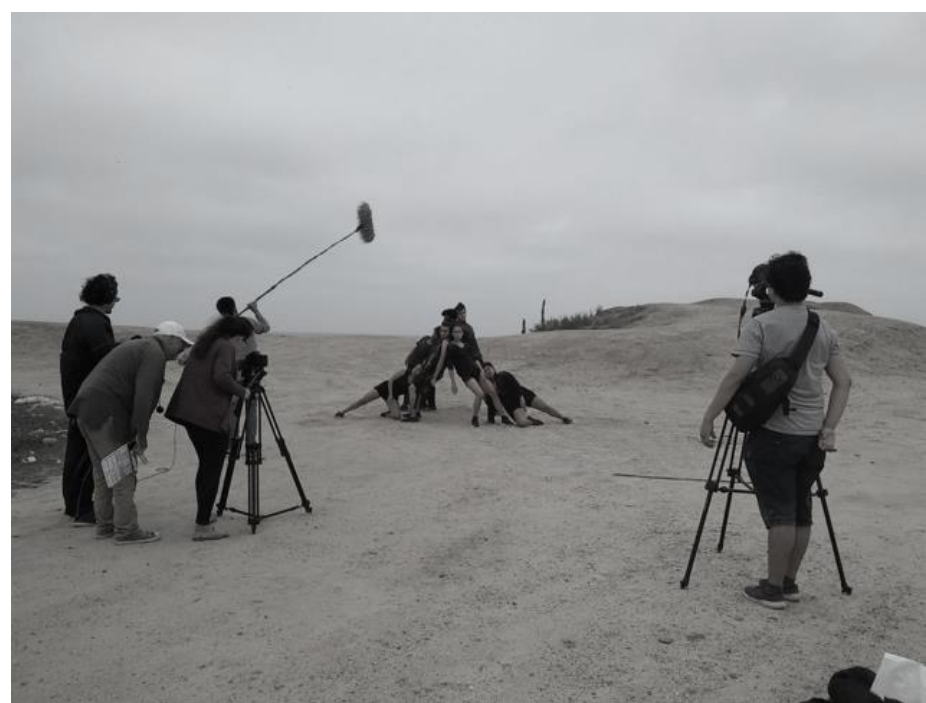

Fig. 6: Realización de la adaptación cinematográfica de la obra coreográfica sigue Corriendo de Talía Falconi. Estreno 2021. Ecuador.

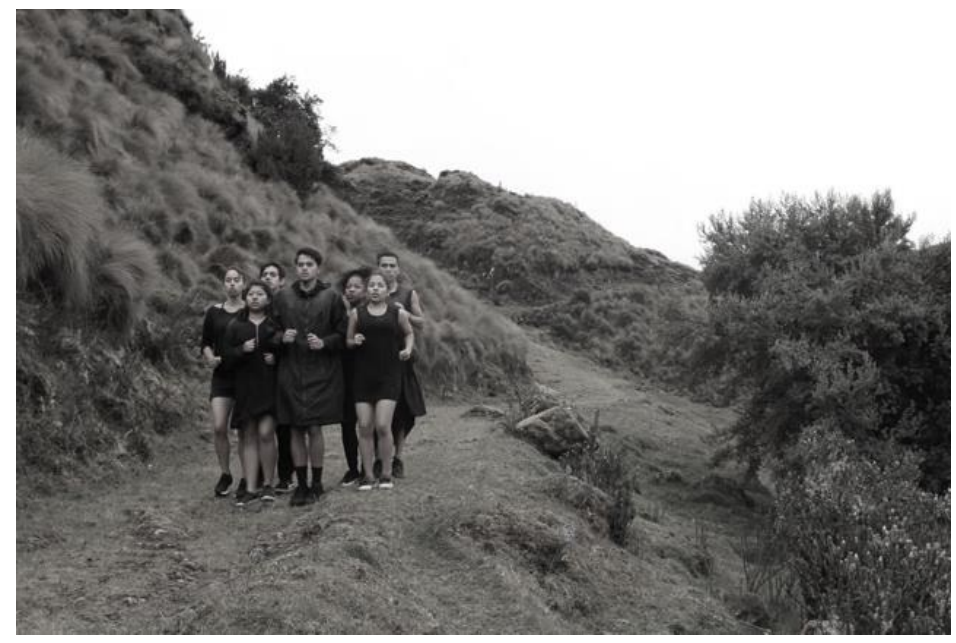

Fig. 7: Fotograma de la película de la obra coreográfica: sigue Corriendo de Talía Falconi. Estreno 2021. Ecuador.

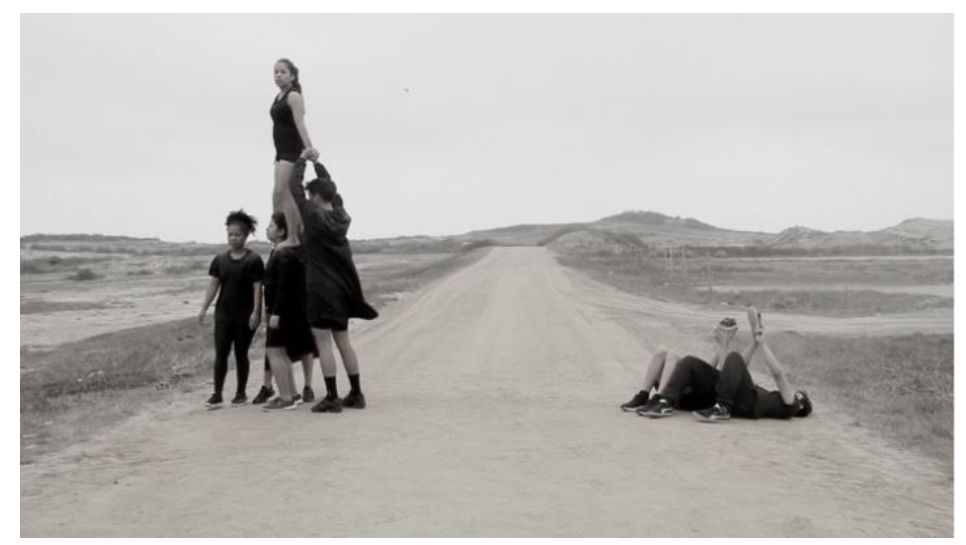

Fig. 8: Fotograma de la película de la obra coreográfica: sigue Corriendo de Talía Falconi. Estreno 2021. Ecuador. 


\section{Conclusión}

Postular una teatralidad desde el campo de la danza es una manera de asumir una hibridez disciplinar. Por otro lado, la comunicación a través de una poética inmanente de la danza, aquella que emerge desde la sensibilidad misma del movimiento tiene el potencial de proponer desde la creación narrativas alternas que pongan en juego contenidos y temáticas vinculadas al ámbito de lo sensorial, emocional y afectivo, que nacen y se desarrollan a través del cuerpo en el espacio y el tiempo, sin necesidad de justificar su comprensión racional y sicológica o desarrollarse a partir de un argumento y/o de narrativas lineales. En ese sentido, se puede hablar de una danza particular que se alimenta de distintas fuentes, donde aspectos musicales toman cuerpo (literalmente), y donde es posible vislumbrar nuevas teatralidades.

A través del estudio y el análisis sobre la escucha y el manejo del ritmo para la generación del movimiento, hay un elemento expresivo fundamental que esta reflexión ha develado: la presencia del silencio, si no hay silencio no hay escucha posible. El silencio se manifiesta en la organización rítmica del movimiento y en la idea de una cierta musicalidad escénica, que trasladada hacia el campo del movimiento expande la visión de lo que entendemos como danza. Asimismo, el silencio entendido como quietud física es capaz de producir una cierta tensión en la escena, una organización del espacio específica, un estado físico que propone interrelaciones particulares.

Estos elementos y su interacción, entonces, componen un sentido de lo dramático, de lo teatral, que no está necesariamente construido en base a paradigmas teatrales propiamente entendidos como tales, sino más bien desde una concepción poética del movimiento.

El movimiento es un fenómeno sensible, capaz de generar procesos de comunicación en el ámbito artístico a través del intercambio permanente de subjetividades, y capaz de detonar, desde esta perspectiva, teatralidades particulares, alternas, en el campo de las artes escénicas contemporáneas. 


\section{Bibliografía}

Barba, Eugenio y Savarese, Nicola. Un dictionnaire d'anthropologie théâtrale: Anatomie de l'acteur. Aveyron: Bouffonneries-contrastes, 1985. Impreso.

Barnsley, Julie. El cuerpo como territorio de la rebeldía. Caracas: Universidad Nacional Experimental de Arte, 2008. Impreso.

Beauvoir, Simone de. ¿Para qué la acción? Buenos Aires: La Pléyade, 1972 [1944]. Impreso.

Bernard, Michel. De la création chorégraphique. Pantin: Centre National de la Danse, 2001. Impreso.

Búfalo, Enzo del. El hogar de los dioses. Caracas: Latina, 2019. Impreso.

Chapuis, Yvane, Gourfink, Myriam y Perrin, Julie. Composer en danse: Un vocabulaire des opérations et des pratiques. Dijon: Les Presses du réel, 2020. Impreso.

Dufrenne, Mikel et al. Vers une esthétique sans entraves: Mélanges offerts à Mikel Dufrenne. Paris: Union General d'Editions, 1975.

Falconi, Talía. La hibridez en las prácticas contemporáneas del Ecuador a partir del retrato

de una generación. Tesis de maestría. Universidad París 8, París, 2021.

---. sigue Corriendo. Video danza. 2 nov. 2021. Web. 2 nov 2021. https://www.taliafalconi.com/.

Falconi, Talía y Valdez, Federico. Música para pelucas. Obra coreográfica. 2011. Web. 2 nov. 2021.

https://taliafalconi-federicovaldez.weebly.com/-muacutesica-para-pelucas.html.

Louppe, Laurence. Poétique de la danse contemporaine. Trad. Antonio Fernández Lera. Salamanca: Universidad de Salamanca, 2011. Impreso.

Nikolais, Alwin. "Day and night: Alwin Nikolais". 5 feb. 2011. Web 20 oct 2021. https://www.youtube.com/watch?v=atmek4ra-UU.

Ohno, Kazuo y Ohno, Yoshito. Kazuo Ohno's world: From whitout and whitin. Middletown: Wesleyan Univesity Press, 2004. Impreso.

Oliveros, Pauline. Deep listening: Una práctica para la composición sonora. Valencia: EdictOràlia, 2019. Impreso.

Pavis, Patrice. Diccionario del teatro. Barcelona: Paidós, 1998. Impreso.

Roquet, Christine. Vu du geste. Pantin: Centre National de la Danse, 2019. Impreso.

Toro, Alfonso de (Ed.). Estrategias posmodernas y postcoloniales en el teatro latinoamericano actual: Hibridez - medialidad - cuerpo. Fráncfort del Meno: Vervuert, 2004. Impreso. 